\title{
Holistic model as a challenge for the medical profession*
}

\author{
Nina PUTAEA**
}

\begin{abstract}
The article presents a doctor-patient relationship model based on the assumptions of a holistic approach to the patient. The author draws attention to selected patients' needs, ones taken into account in this model. These are the right to autonomy and an individualised approach to the patient. These issues, considered in relation to philosophy, show a conflict between patients' values and aspirations and doctors' values and their experience. Nowadays, patients' needs are protected by consumer rights as well as being strengthened by postmodern philosophy, which shapes society's awareness of various definitions of health and underlines the right of the individual to self-determination. This situation creates an incredible challenge for doctors because attempts to assist is, according to medical knowledge, associated with an inevitable collision with the subjective perception of a patient's health. Because of this issue, the author considers it necessary to enquire about the needs and aspirations of not so much patients as doctors themselves. It is assumed that the definition of what is currently important for this group determines the scope of any possible admission or intentional ignorance of patients' needs.
\end{abstract}

\section{KEYWORDS}

axiology; doctor-patient relationship; health; medical ethics

* This article attempts to present a brief summary of the results of the project called 'Research on the experience of values' funded by MNiSW in 2018.

** Ph.D. candidate at the Department of Philosophy, The Pontifical University of John Paul II in Cracow, Poland. E-mail: ninaputala@gmail.com. 


\section{HOLISM IN MEDICAL PRACTICE}

The recent development of the doctor-patient relationship in Europe and the United States has been one orientated towards patients' needs. The focus on patients' rights seems justified given the dominant role of doctors. The holistic model of medicine has become a driving force in seeking improvement in communication between the parties.

Since the second half of the twentieth century it has been postulated to shift from a biomedical model to a holistic approach to man, here including human health. This holistic orientation also means taking into account the psychological, social and spiritual area of the patient along with the physical approach to their health. All these factors have been found to be interrelated on the path of development of patient well-being. They are being balanced while taking into account the individual needs of each of them (Schwarz et al., 2011; Stineman, 2011). The holistic model corresponds to the policy of the World Health Organization, which defined health in 1946 as complete physical, mental and social well-being. ${ }^{1}$

Holism in medical practice is implemented in a couple of ways: (1) a subjective relationship with the patient, (2) the complementarity of medical specialisations, (3) the unity of the therapeutic team, (4) alternative medicine as opposed to conventional medicine (Szary \& Knotowicz, 2014). ${ }^{2}$

In a holistic model, a new way of understanding patients emerges, when compared to a biomedical approach. The specific characteristics of this approach are particularly visible when the holistic model is opposed to the biomedical model. Jean-Christophe Mino and France Lert indicate that in the biomedical model the patient is perceived as a "clinical case", subjected to an objective evaluation. This evaluation focuses on the body and does not take into account the personal aspect (Mino \& Lert, 2005). The holistic model goes beyond this approach, introducing new, wider criteria of patient perception, and this may be considered as introducing the non-corporeal side of medicine into the doctor-patient relation (Bandol, 2015).

However, going beyond the organic system is associated with an issue of a very wide interpretation horizon in relation to any philosophical definition of a patient as a person. While the biomedical approach can be associated with naturalism and mechanistic monism (Bandol, 2015), supported by the dualist philosophy of Descartes (Bardziński, 2017), it is difficult to provide a clear philosophical background for the holistic model. Enough to say that the

\footnotetext{
${ }^{1}$ New York, 19 June - 22 July 1946; signed on 22 July 1946 by the representatives of 61 States (Official Records of WHO, no. 2, p. 100) and entered into force on 7 April 1948. The definition has not been amended since 1948 .

${ }^{2}$ In this article the discussed difficulties relate mainly to attempts to implement a holistic approach in the first sense, and to a lesser extent they also refer to holism in the second sense.
} 
holistic model claims to consider a person in a way that also takes into account the specific characteristics of their mind, besides their physical dimension. In this approach, the mind would be something more than just the equivalent of an organ (Bandol, 2015).

An assumption as to the specificity of mental states may be justified by the emergence concept, according to which the specifics of a higher order cannot be deduced from the specifics of a lower order (Bandol, 2015). Therefore, studies on human mentality must be new, in relation to methods derived from monist naturalism.

However, reference to the emergence theory still leaves the holistic concept without a clear philosophical background when considering the psychophysical problem. It can be imagined that Cartesian philosophy, efficiently supporting the biomedical model, can also support proposals of holism (Schwarz et al., 2011). However, such a proposal would concern referral to Cartesian philosophy in its full meaning (contrary to its narrow understanding in the biomedical model). Medicine based on a biomedical paradigm has mainly adopted the concept of the human body as a mechanism. As Kazimierz Mrówka notes: "The Cartesian cogito gives body to the science, which will perform a specific autopsy on it" (Mrówka, 2002: 60). Holism would introduce to medicine all that is non-corporeal. Therefore, while remaining within the sphere of Cartesian philosophy, the thing called by Descartes the "thinking substance" (res cogitans) should be restored to its proper place, besides the concept of the human body as a mechanism.

However, this solution raises some objections. In the dualist concept, the mind is a separate substance that cannot be brought down to an organisation characteristic for the body. Although Cartesian cogito calls for the patient to be considered from a wider perspective, yet at a level of practical medicine this dualism is problematic. One of these difficulties is providing justification for a causal interaction between two different substances, the body and the mind (Schwarz et al., 2011).

Another way for considering this psychophysical problem derives from Aristotelean and thomistic philosophy, although this proposal may give rise to concerns due to the strong considerations of human nature as related to the existence of transcendence. As Filip Bardziński notes, "After all, in pluralistic societies different, frequently competitive models of the good life undermine the possibility of such a foundation for any holistic understanding of human nature" (Bardziński, 2017: 98; trans. N.P.). The author proposes supporting the idea of holism with Maine de Biran's anthropology and with Michel Henry's phenomenology of the body, by understanding the holistic model of human nature as "I" incorporated (Bardziński, 2017).

A proposal to support the idea of holism with philosophical concepts: Aristotelean and thomistic, M. de Biran's, or M. Henry's, appears interesting, but 
today they do not have a decisive influence on the development of a holistic approach to the patient. Holistic concepts are based on a postmodern perception of diseases as a cultural phenomenon (Bardziński, 2017: 103) - and this is an important remark from the point of view of the main issue discussed in this paper. This paper raises the question of challenges associated with the current holistic models for modern medical practice, and not a valid proposal to implement holism. The study concerns the idea of holism inspired by Postmodernism - as a currently influential concept (Mrzygłód, 2012) impacting patients' attitudes (Barbaro, 2008).

In this postmodern view, it is difficult to find a single definition of a human. This fact is reflected in the very literature promoting a holistic approach in medicine. Paradoxically, although an ambitious direction of understanding health as combined physical, mental and social well-being prompts one to define a merger of the body and the mind in man, yet in medicine holism is based rather on an encouragement to go beyond a naturistically understood psychosomatic system, without providing an explanation as to what this organisation of the human being outside "the body" should be, for example, how the spiritual aspects coexist with the corporeal reality. The concept of holism, discussed from the point of view of different divergent philosophical perspectives, does not provide a clear solution concerning its practical implementation. In this respect, the biomedical paradigm interested in the "body" exceeds the humanist approaches. It develops clear standards and provides specific, evidence-based results.

However, despite the lack of anthropological assumptions, the holistic model still remains an important perspective. It is not associated with any specific definition, yet several recurring features of the holistic approach to a patient can be noticed, ones frequently included in papers promoting this model. They include: a patient at the centre of the model, a respect for patient autonomy (related to an individualised approach to every person), and the subjective relation of the doctor and patient. It appears that it is these features that set the direction for changes in the doctor-patient relation, and it is mainly to them that the term "holism" refers in practice. Therefore, these features will guide further considerations concerning challenges posed to medical practice by a holistic model.

However, defining the new model through such features has its positive and negative sides, which become clear with an analysis of the use of the holistic approach. One of the examples of the implementation of holism is a concept referred to as the theory of "total pain" described by Mino and Lert. The theory of "total pain” was formulated by Cecily Sauners, a founder of St. Christopher's Hospice, setting a new holistic direction for palliative care in France (Mino \& Lert, 2005). The term of "total pain" is defined as follows: "pain is no longer a simple symptom that refers to an organic lesion or physiological malfunction, 
but an evil in itself" (Mino \& Lert, 2005: 229). In Mino and Lert's model the mentioned "evil" appears to be defined subjectively. It is the patient who specifies where the "evil" lies in the experienced pain, together with possible methods for coping with this pain - as assumptions of the proposed concept indicate. They are as follows:

1. The patient is at the centre of the holistic model.

2. In the holistic model, the patient is "a riddle to be solved". The personnel's task is to search for expressions of the patient's inner self by collecting the following information: psyche, history, culture, beliefs, social relations, clinical status, medical history, professional career, family history and relations, personality traits, desires, opinions, will, and experiencing of disease. Using these details, a "picture of a patient in total pain" is created, which forms the basis for further actions.

3. The approach to the patient is to be individualised. Each patient experiences different types of medical, mental or social pain.

4. Different layers of a person are considered: physical, mental, social, and spiritual. A multidisciplinary team of specialists must reach each of these realities, to perform "pain judgement" and create a picture of the "inner self" instead of a diagnosis.

Data collected from the perspective of different fields are integrated and interpreted. Mino and Lert describe this stage as follows:

The biomedical norm is no longer the dominant norm to which all players must refer. It becomes subordinate to other imperatives. Its relevance depends on the patient's situation, expectations, and will. [...] Ideally, themedical decisions will be modulated explicitly according to the personal, family and social contexts (Mino \& Lert, 2005: 232-233).

The above example presents holism as a model focusing on a patient's needs, ones read in a multidimensional experience of pain (physical, mental, spiritual, and social). The idea of holism expressed in the above ideas prompts one to focus on the subjective doctor-patient relation. In this respect, the holistic model is worth notice. However, difficulties that may arise due to the fact that the specified features are not supported by a specific philosophical anthropology may also be noticed. This problem can also be analysed on the example of the implementation of holism through the concept of "total pain". In this approach, the work of specialists from various fields has resulted in a mosaic of various information about a patient, collected using different methods. The integration of all these views is pursed, to determine further management. However, the way to interpret the patient data collected remains unresolved. It is not clear which information should be considered more important and decisive. In the proposed model, the biomedical aspect is not the most important; 
however, at the same time, it is still unknown which other aspect is the leading one and who decides about the hierarchy of importance for the described individual layers of man (physical, mental, spiritual, and social).

Possibly, the answers to these dilemmas should be sought in the direction set by WHO, which refers to well-being in its definition of health. Ernst R. Schwarz et al. has noticed that:

The concept of well-being is defined as the individual's personal experience of a state of relatively ideal being, as that state is represented by and mediated through the values embedded within a given sociocultural environment. For example, cosmetic plastic surgery - even when not always medically indicated - often enhances well-being (Schwarz et al., 2011: 352).

According to this direction, the hierarchy of importance is culture-dependant, yet eventually, the key to alleviating the pain is hidden in the patient's mind, and finding this idea is a task for a specific team of specialists. It is the patient who interprets the concept of their own well-being; for example, determines whether the physical aspect, disease considered in its religious aspect, or mental comfort is the most important for them. However, this approach puts the doctor (still being a representative of knowledge derived from the biomedical paradigm) in a position subordinate to the subjective expectations of the patient and culturally relative values, and this may lead to many difficulties.

Max Scheler, in considering the foundations of specific sciences, notes that each method concerning man assumes some kind of philosophical anthropology hidden behind it, which guides these methods to specific objectives (Scheler, 1958). Therefore, it is not the promising features of the holistic model that may be decisive for its final assessment (positive or negative), but, actually, the concept of man on which this model is based.

Medicine is this branch of science in which conscious and clear determination of philosophical foundations of the implemented method would be of particular importance. The concept of holism allows for a significant freedom here. By placing the patient in the centre of the model, it shifts the decision for "giving priority" mainly to the patient. Currently, in the era of Postmodernism, the specialist must somehow put aside any judgement of their own set of values and open to multiple interpretations of what is good for the patient (Barbaro, 2008). Therefore, when considering the main issue of the paper current challenges associated with the holistic model - I refer solely to the listed features of the model combined with postmodern philosophy. I leave aside the question of the different philosophical concepts on which holism could be based.

This paper is also limited to reflections on the difficulties which the listed features may pose to doctors. In the partnership model, doctors may have 
difficulties with the procedure they think is best if patients do not share their opinion (Nilsen \& Malterud, 2017). The will and subjective experiences of the patient are increasingly required to be included in medical procedures. As a result, there is also the question of the doctor's role - about the doctor's ability to act freely following his or her values and knowledge and the purpose of medicine. In the context of these phenomena, it seems reasonable to ask what values are essential for contemporary doctors; whether they are consistent with the expectations of patients and consistent with the requirements that are set for doctors. These doubts are valid in the face of changes in the perception of the doctor-patient relationship.

\section{PATIENTS' NEEDS AS DETERMINANTS OF CHANGES IN THE DOCTOR-PATIENT RELATIONSHIP}

The question about the practical implementation of the way in which health is understood holistically by the international community is still valid. In medical practice, this approach is employed with difficulty (Pederson \& Emmers-Sommer, 2012; Chuengsatiansup, 2003). The holistic model does not give such spectacular results in diagnostics and therapy as those provided by biomedical medicine (Stineman, 2011; Diaz \& Honea, 2017). This does not mean, however, that the paradigm shift brings no positive results. The holistic model has contributed to a change in the doctor's attitude to the patient. It sets out more comprehensive requirements for medical personnel, motivating healthcare workers to greater effort, rather than focusing exclusively on biomedical issues (Mino \& Lert, 2005).

The way to approach these concepts is by focusing on: patient autonomy, a partnership model, and an individualised approach to the patient. It is strengthened by postmodern philosophy and consumer rights policy. These characteristics of the holistic model will be presented below and later followed by critical examination.

Patient autonomy is one of the features of the holistic model. In medical ethics and bioethics, the concept of autonomy was introduced for practical reasons. It was considered to be helpful in solving doctor-patient dilemmas more so than the concept of the "dignity" of the patient and the concept of the "good" of the person, introduced by traditional and personalist ethics. Autonomism has become an incentive to look for improvements in the doctor-patient relationship. Changes in this direction were emphasised in the 1980s as a result of the discussion on the principle of autonomy indicated by Tom L. Beauchamp and James F. Childress in Principles of medical ethics (Biesaga, 2013). The authors set out four rules to be obligatorily followed and practically applied by doctors. Respect for the patient's autonomy was indicated as one of 
the principles alongside nonmaleficence, beneficence and justice (Beauchamp \& Childress, 1994). Beauchamp and Childress indicate that respect for another person's autonomy implies at least the recognition of an individual's right to have views, make decisions, and take actions in accordance with personal values and beliefs (Beauchamp \& Childress, 1994).

The existing legal and normative provisions (Constitution, Penal Code, the Act on the medical and dental professions, Code of Medical Ethics and international conventions) emphasise and strengthen the position of the patient in the broader view of human rights - including one's freedom to make decisions about one's own life. The patient's autonomy is protected by laws that the physician must follow while bearing the consequences of having failed to take proper action.

The partner relationship is the next presented feature of holistic model. In bioethics, models are created to illustrate the possible types of communication between the doctor and the patient. They emphasise the importance of cooperation between the patient and the doctor, which corresponds to the gradual personalisation of medicine. The earlier paternalistic model has rarely been said to be right, except in situations where the patient's condition makes it impossible for the patient to make informed decisions. The initial dependence of the patient on the physician, which is already marked in the first described model, has, over time, increasingly given way to a partnership model in which the doctor encourages the patient to be more active; thereby, to express his or her own needs and values (Mino \& Lert, 2005; Bandol, 2015). The introduction of such changes is justified by the need to consider the patient's right to self-determination. Emphasising the needs of the patients is all the more desirable when taking into account the weaker position of the patient, who asks for help because the doctor is the only one who has the professional knowledge and medical possibility to give such help (Beauchamp \& Childress, 1994). In the partnership model the doctor has no freedom to take independent decisions on how to fight an illness but must use skilful communication to involve the patient in the decision-making process so that the latter can identify the meaning of the proposed procedure and have a better understanding of his own well-being. ${ }^{3}$

${ }^{3}$ In bioethics, a detailed distinction between doctor-patient relationship models can be made, e.g., according to Ezekiel J. Emanuel and Linda L. Emanuel. These are: (1) The paternalistic model, sometimes referred to as the parental or priestly model. The paternalistic model assumes that there are shared objective criteria for determining what is best for a patient. In this model, the physician acts as the patient's guardian, articulating and implementing what is best for him/her. The physician provides only selected information that will encourage the patient to a consent. (2) Informative model, sometimes called the scientific or the consumer model. Here, the physician must provide every medical piece of information to the patient. The patient is the one who chooses the best treatment from his own perspective. The patient controls his/her own health condition. The physician is a purveyor of technical expertise, 
The increased interest in the patient's needs is also related to the commercialisation of medicine. Along with socio-economic changes, the ethos of the medical profession and the doctor-patient relationship has altered considerably. Since patients have been legally referred to as "clients", a broader perspective has opened up for patients to express their expectations, strengthened by a set of consumer rights. Preparing an attractive offer for the greatest possible number of clients has become a challenge for private healthcare institutions (Heubel, 2000; Relman, 1980).

Patients search through wide portfolios of medical services for the most suitable solutions. It is difficult to say what leads them when choosing a doctor. Online doctor assessment portals are popular. They provide many people with valuable tips about specific specialists. Such portals are characterised by the lack of a top-down criterion determining what a good doctor's job means. Internet users can share their own individual opinions about a specialist identified by name. Patients assess various aspects of the physician's work that are as different as their needs, sensitivity or what the experiences of meeting that particular specialist are.

The medical profession is being constantly evaluated on a social level. This trend is additionally strengthened by the activities of institutions that monitor changes and certify health services. The results of research on patients' opinions about doctors' work are presented on an annual basis. The assessment takes into account, among other issues, the time devoted to consultation, the ability

a servant to a patient's needs. (3) The interpretative model. According to the interpretative model, a patient's values are very important. The physician must include these values in his medical choices. The interpretative physicians provide the patient with information on the nature of the condition as well as the risks and benefits of possible interventions. Because this patient's values are essential, the physician should help the patient articulate his or her own values. He serves as a psychotherapist, assisting in the process of self-understanding. In this model, the physician is engaged more in the intimate and unconscious world of the patient than as it is in the informative model. (4) The deliberative model. This model aims to help the patient determine and choose the best health-related values that can be achieved in a medical situation. The physician acts as a teacher or a friend. He or she engages the patient in a dialogue on what course of action is the best. The final decision is made by the patient (Emanuel \& Emanuel, 1992).

The above propositions are positioned in a holistic approach to the patient in the following manner: in the paternalistic model, mainly objective values come forward. The holistic model departs from the paternalistic approach. Patients' values are considered in the informative and the interpretative model. These models support the idea of "a patient in the centre of the holistic model". The deliberative model could meet the idea of a partnership. At the same time a doctor's values are important in this model (medical well-being). Ultimately, however, it is difficult to say whether such a model leads to an agreement. In this model, the physician defines "patient's health", while in the holistic model the patient ultimately determines the understanding of his own "health". Thus, there is a conflict between two interpretations of health: understood in the biomedical and the holistic paradigm. This phenomenon will be discussed further in this article. 
to explain recommendations, the opportunity for the patient to ask questions and express concerns and the ability to involve patients in the decision-making process regarding the treatment (Health at a glance, 2015: 161). These elements are conducive to the patient's participation in the process of treatment and the choice of methods. This can be translated into the patients' ability to reveal their own axiologies.

The need to approach each patient on an individual basis is also emphasised in considerations of the doctor's role. This is favoured by postmodern philosophy, which proclaims the principle of "radical pluralism". According to this principle, different patterns of behaviour, and any lifestyles or variable ways of interpreting phenomena are acceptable (Welsch, 2008).

Postmodern is a stage in history in which radical pluralism as a basic principle of societies, becomes real and recognised, and pluralistic patterns of meaning and action gain an advantage and even become obligatory (Welsch, 2008: 8).

Freedom is, among other things, understood as a free detachment from the hegemony of the concept of one truth. Each person has the right to choose values that are important to that person, without yielding to the claims of individuals, arrogant in the light of the principle of pluralism, to the right to absolutize their assertions as binding other people. Postmodernism will attempt to show there is no justification to accept the only definition of the truth.

Postmodern principles are reflected in the healthcare sector (Barbaro, 2008). Medical truth is only one of many, and each time it must be confronted with the patient's individual attitude to the problem of one's own health. The contemporary patient does not remain passive and confidently subordinated to the doctor's actions. The popularisation of medical knowledge on the Internet and modern communication technologies make medical knowledge widely accessible and easily transferable. Patients increasingly often try to self-diagnose, using simplified descriptions of various kinds of symptoms available on the Internet (Anwar \& Khan, 2013). Having a rough idea about the treatment, the patients may expect their intuitions about their own therapy to be taken into account.

In the coming years, patients' needs shall continue to be the focus of medical staff's activity, be a field for numerous research activities and set further innovations in the service of the patient. Such a trend is somewhat associated with optimistic results, which seems to be communicated by the position taken by many healthcare institutions and organisations. Scandinavian countries are the leading region of Europe innovating in this area. In Norway, the governmental health policy document for 2016-2019 states that patients are often the most radical agents of change in the healthcare sector (Meld. St. 11, 2015-2016).

In summary, the approach to the patient postulated today is outlined above. The need to focus on the patient's needs has been reflected in various 
governmental and non-governmental initiatives. Although the direction of the change is ambitious, it is noticed, however, under a more in-depth analysis of the issue, that it generates many difficulties in the work of physicians. The next section will discuss some of them.

\section{DIFFICULTIES ASSOCIATED WITH TAKING INTO ACCOUNT PATIENT NEEDS BY A DOCTOR}

The idea of a holistic model, followed by the emphasis on the importance of autonomy or an individual approach to the patient, may be associated with numerous difficulties in application. It is a brave doctor who wants to cross the biomedical paradigm and encourage the patient to reveal the broader background of the disease being experienced. Unfortunately, this act of bravery can lead to a misleading of clear medical procedures as well as decline doctor's leadership. Slogans about a holistic approach to patients and focusing on their individual needs hide many difficult challenges. Therefore, it seems reasonable to analyse at least some of them.

The first difficulty appears in the course of implementing the principle of autonomy (Schwarz et al., 2011) as mentioned in the previous section. This must be taken into account when addressing a patient's needs. However, the question arises about the source of autonomy - what is human freedom, for example, to choose individually important values and what does this freedom manifest itself through? It is not easy to determine whether a person with disturbed bio-psycho-social functions is able or unable to make autonomous choices. How is the doctor supposed to reach the other person's world of values or separate the crowd of impressions that the patient has about his or her illness from the relevant information required to carry out the diagnosis and choose the best therapy?

In philosophy, the issue of autonomy is widely considered, yet an unambiguous definition of this concept is elusive. Autonomy is expressed differently according to how man is described - or more broadly - the acceptance or rejection of metaphysics. The decisions taken in this respect determine the way in which an individual's autonomy is interpreted. Autonomy associated with the reasonable acceptance of a universal duty, the conscious fulfilment of which is only an expression of authentic human freedom, as in Immanuel Kant's works, shall differ from the autonomy derived from the very will to have power, a creative need to express oneself, which Friedrich Nietzsche liked to recall. ${ }^{4}$

${ }^{4}$ The concept of autonomy is not explicit (Dworkin, 1988). Within medical ethics and bioethics, the consideration of autonomy is often confined to the dispute between Kantian philosophy and John S. Mill's philosophy (Stammers, 2015: 201). In this context, "the respect 
On the level of bioethics, too, there are discrepancies in the definition of autonomy, depending on the philosophy on which they are based. At the beginning of the article, the doctor's rules of conduct according to Beauchamp and Childress were mentioned. Their critics note that the very concept of autonomy described by these authors has not been explicitly referred to a specific concept of man and the resulting definition of autonomy. This can create problems on the level of specific solutions (Hołub, 2013). One of the difficulties is to determine when the patient's decisions are an expression of free acts.

Kazimierz Szewczyk, in considering the possible concept of man that underlies the principle of autonomy, points to Cartesian duality (Hołub, 2013). $\mathrm{He}$ notes that Beauchamp and Childress separate the rational "autonomous self" as belonging to the human being from changing states such as pain, suffering or illness. The doctor's role, according to this approach, would be to distinguish the patient's rational moments and help verbalise them when making important decisions (Szewczyk, 2004). However, there are no solutions on how the doctor should discern these conscious acts from, for example, changeable affective states, in order to take them into account.

In this approach, it should be decided as to whether the disease affects the "rational self", making it impossible to make autonomous decisions. An example of this may be patient consent to undergo risky surgery. While assessing medical issues, the doctor would additionally be investigating whether this person was expressing his or her own decision from the depths of their individual freedom. In such a case, the doctor would have to go through the whole expression of the patient to find some unchangeable centre forming the basis of free self-determination - if there exists such an independent "rational self" at all. Moreover, the doctor would have be able to distinguish them from the

of autonomy" is also considered in terms of Beauchamp and Childress. In this article, the interpretation of autonomy is limited to this suggestion. This choice is not accidental. The "principle of autonomy" within this article is considered in the context of a holistic model, giving up the specific definition of a human being. (see section 1). The Bauchamp and Childress proposal is an example of moving away from a clear definition of man and his autonomy in favour of describing the principle of the autonomy itself. Bauchamp and Childress replaced the principle of "respect of the person" with the principle of "respect of autonomy" (Hołub, 2013).

As a side note, it is only worth observing that a completely different approach to the problem of autonomy is presented, for example, by Paul Ramsey (Ramsey, 2002), who expresses his views in this regard in the book titled The patient as a person, which is discussed within the bioethics community. According to him, the patient as a person is a compass for medical ethics and his autonomy should be read as such. A personalistic understanding of man as a person is the foundation of social interactions, especially when it comes to medical practice, which is practiced on the ethical level in the doctor-patient relationship. The concepts of dignity, respect, the ability to listen, sensitivity to suffering as well as understanding together with a patient's autonomy all originate from Christian ethics, which Ramsey does not hesitate to refer to, repeatedly using the term "a full person" instead of the term "a person". The patient's autonomy must be seen from the perspective of treating patients as ends and not means. 
patient's fluctuating statements. It is difficult to say whether a paralysed person experiencing severe pain and taking a decision to undergo risky surgery is rising to the level of a rational analysis of his or her own situation or is simply undergoing changeable emotions. ${ }^{5}$

Even if autonomy does in fact lie in the person's rationality, the whole dynamic nature of the person serves as the communication channel. Existentialists make a valuable reminder in this regard. In their philosophy, man is formed based on suffering, fear, and a sense of nothingness or loss, and not in isolation from these experiences. Martin Heidegger notes:

In the clear night of the nothing of anxiety the original openness of beings as such arises: that they are beings - and not nothing. But this "and not nothing" we add in our talk is not some kind of appended clarification. Rather it makes possible in advance the revelation of beings in general. The essence of the originally nihilating nothing lies in this, that it brings Dasein for the first time before beings as such (Heidegger, 1929: 6).

According to this approach, a person somehow automatically takes decisions under the burden of existence, which in turn is associated with fear or suffering that is revealed through the experiencing of the illness. It is impossible to assess what the right decision is, one coming from the depths of the "autonomous self". The role of an arbitrator, advisor or companion in matters related to the risk of the loss of life or significant deterioration of health appears to be extremely difficult. Antoni Kępiński expresses the impossibility to ultimately get to know the patient. He indicates that the patient is "unmarked", thus stressing the difficulty in identifying the truth about another human being and the impossibility of going beyond assumptions made about him or her (Kępiński, 1977: 44).

In connection with the above, it is not easy to say what a doctor-patient dialogue aimed at stimulating autonomous rational acts in it would be. Even the greatest specialists may distance themselves from this task in advance.

Along with the increase in the patient's autonomy, there also occurs another significant problem related to reconciling the values essential to the doctor with those essential to the patient. When an action is to be carried out through

${ }^{5}$ As a rule, the psychiatrist looks after the patient's ability to make informed decisions. Psychiatric consultation is required when a patient is diagnosed with a mental disorder that prevents him from giving informed consent to the surgery. Psychiatric opinion, however, is considered unnecessary for patients who do not show any psychiatric disorders. At the same time, it cannot be assumed that such patients have no problem with making independent decisions. Following the principle of autonomy, it would be appropriate for every doctor who has contact with the patient to take on the responsibility associated with a more in-depth look at the problem of the freedom of the person. Thus, Beauchamp and Childress' postulate of reaching the patient's "rational self" is an ambiguous and difficult-to-achieve challenge. 
the cooperation of several people, a conflict may occur due to the collision of the various value systems that these people represent. The implementation of values that are important to the patient depends on the doctor's recognition of these values. The doctor may violate or reinforce the value system that is essential to the patient. Similarly, the patient may take into account or disregard the axiological belief, knowledge or realities of the physician's work. How can these two worlds of values - the doctor's idea of his own work and the patient's idea of how the doctor should behave towards him or her - be coordinated. According to Robert M. Veatch, the dialogue is not easy, because the patient and the physician assume different axiologies (Veatch, 1979).

Many examples can be given to illustrate the conflicts related to the doctor's inability to conform to the values important to the patient. This problem occurs when segregating the superior and inferior needs of different patients. The limited financial resources of healthcare institutions force the doctor to decide who should receive specific benefits. The burden of such a decision arises even in complicated cases, for example, when a doctor has to decide whether a patient diagnosed with cancer should undergo costly treatment in the event of a poor prognosis and little chance of a healthy recovery.

Commentators of the Principles... note that Beauchamp and Childress deal with the dilemma related to the conflict of reason by subjecting the doctor's rules of conduct to standards that are culturally relative. They have only set a moving framework for the definition of autonomy, while keeping the need to respect it relative to the cultural context. In this approach, the norm is established by "colloquial morality", which is constituted by the acceptance of certain behaviours in a given social group, and the rejection of others (Hołub, 2013). This standard is a variable one, dependent on the development of society. An obligation that has taken a long time to be recognised in a given group can be suspended due to the need to undertake another action that demands to be fulfilled as a more urgent obligation (Beauchamp \& Childress, 1994). The views of the authors of the Principles... are close to the utilitarianism of John S. Mill (Beauchamp \& Childress, 1994), where the decision is based on the calculation of benefits for the largest possible number of patients while the risk is being determined.

An attempt to apply the principles of utilitarianism to the aforementioned case of a cancer patient reveals difficulties. The doctor's role seems particularly difficult and thankless when the doctor must fail to meet the expectations of the patient who would like all the possibilities to save his or her life to be used. The patient is not subjected to an expensive therapy because the chance of survival is lower than those of patients with better prognoses. The autonomous individual that is the patient does not necessarily see the interests of society. It is difficult to expect a sick person and his or her family to start to count social benefits in the face of their own tragedy. A doctor who sees the social 
interest must act against the needs of an individual patient and express his objection to meeting patient expectations. In Poland, the doctor is responsible for providing information about this kind of refusal. It is hard to imagine how he could do this without violating - in Beauchamp and Childress' words the patient's right to act consistently with the patient's values (Beauchamp \& Childress, 1994: 156).

This is one of the problems that arises in the doctor-patient relationship when both parties' objectives are being pursued. In this case, the doctor not only has to be guided by what he personally considers to be good for the patient but also to take into account the values that he represents as an employee of a particular healthcare institution with which he identifies more or less (Relman, 1980).

Another challenge that the doctor has to face is the need to go beyond his field of specialisation (Szumowski, 2007). Being attached to the knowledge within a selected scope may hinder a broader perception of the problems that patients bring up (Szumowski, 2007). Meanwhile, according to the holistic model, the contact with the patient requires not only a personal relationship to be built, but also specialist knowledge to be enriched with insight into other areas of medicine.

This kind of synthesis helps make for a better diagnosis. Therefore, the doctor is not only responsible for updating knowledge within his or her own field of specialisation but it seems equally important to be prepared to skilfully combine different ways of capturing the same case. Władysław Szumowski notes:

Adding a dozen or so analyses alone will not produce a diagnosis. Clinical thinking requires making a synthesis, grasping the whole which is more than a mere sum of the individual compartments of the human being; however, the charm of analyses is so great that, for many physicians, their number is almost synonymous with medical science. [...] Additionally, pathology was isolating the human being from the social, physical and cosmic environment; it disregarded the relations and laws of harmony between the living system and the universe. In separating the body from the soul, the unity of the individual was lost (Szumowski, 2007: 77).

Difficulties for doctors also occur on the part of the patients themselves. The widespread availability of medical knowledge mentioned previously generates both benefits and problems. Patients taking information from sources of varying reliability acquire specific beliefs about their state. The patient attached to an idea of his or her own illness and the methods used to treat it may expect the doctor to implement an idea to fight the disease that has already been "prepared" by the patient.

The patient's wish is to be healthy. However, the patient does not have the structured knowledge and experience to verify his or her beliefs about 
treatment methods in the broader sense of scientific discoveries. As a consequence, the patient cannot become a controller of the doctor's actions. Doing so, the patient may cause tension between him or her and the specialist. It will not be easy for a doctor to meet a patient who comes with a specific idea about the diagnosis and therapy. Reducing the specialist's work to meeting expectations may violate his or her autonomy. A group of Norwegian researchers notice that doctors feel particularly uneasy in situations when they refuse to accept patients' demands (Nilsen \& Malterud, 2017).

Following the requirements of the holistic model, the doctor should win the trust of the patient to make the latter feel invited to tell about his or her illness in its various manifestations - physical, mental, social and spiritual. As a consequence, the patient may think that the doctor will use all possibilities to help him. Meanwhile, the doctor, aware of the difference in expectations, of medical limitations and of the doctor's own abilities - may, even during at first, try to inhibit the patient's excess of trust and narrow the conversation to focus strictly on the diagnosed disease. In protecting themselves against conflicts with persons showing demanding attitudes, or not wishing to let down people with inappropriate expectations, the doctor may (and probably unfairly or unnecessarily) inhibit the willingness of most patients to confide. This, in turn, may make it more difficult for patients to communicate the history of their illness.

A difficult challenge for the medical profession is the postmodern principle of pluralism, allowing for multiple positions in defining health. Searching for the good of the patient in the light of his or her needs seems to be an unfeasible task, which is evidenced by the statements published on websites. In the comments posted by patients satisfied with their treatment, the medical good often mixes with kindness. One may doubt whether an excellent doctor is one who heals well, or one who treats well because he or she is kind. There are no explicit criteria available in this area, which makes it difficult to determine whether the patient's expectations of a doctor's conduct are legitimate or whether they have become unjustified claims that defy the very goal of medicine.

Although doctors are prepared to guide patients using medical knowledge and following convictions acquired alongside medical experience, they must take into account patients' individual needs. If the patients value body aesthetics higher than vital efficiency, then they will hardly agree, for example, to have a disfiguring amputation which the physician perceives to be the best solution. Bringing the bio-psycho-social condition to the parameters closest to the standard is not a solution. The subjective feeling of health also indicates what the patient will do next for his or her well-being. The problem recognised in this respect is that the doctor can no longer freely refer to values important to him. The doctor is forced to remain neutral towards his or her own axiology (Biesaga, 2013). 
Since there is no explicit and clear criterion for what is right, even the most essential needs are only subject to negotiation (Biesaga, 2013). There is the possibility for a doctor's knowledge to clash with a patient's intuition. In bioethics, theoretical approaches to the doctor-patient relationship regulate this dispute over various positions, such as the negotiation or contracting model. Although these proposals may take into account various types of values that are important to the doctor or the patient, the contract rules devalue the ethos of medicine to any meaning depending on the current needs of the parties. In this perspective - as Edmund D. Pellegrino emphasises - the patient remains (paradoxically, contrary to the rules of equality and respect for autonomy) in the position of being the weaker. In fact, the patient does not have medical knowledge and negotiates with distress and fear for their own cause (Pellegrino, 2008). Any attempt to apply models of the doctor-patient relations in which autonomy is emphasised without a reference to the nature of the doctor-patient relationship itself, may, in many cases, turn against the patient himself (Biesaga, 2013).

The problem of the lack of trust in the knowledge and experience of doctors may be related to the widespread distrust of expert systems (Giddens, 1990). Because of this phenomenon, the doctor has to in fact build an entirely new area of trust between him and the ill person. A reference to specific patterns, traditions, experience or specialist knowledge may turn out to be insufficient. It seems that the chances to build a favourable treatment relationship with the patient increases with effective communication. However, is this enough when there is no consistent axiological background to the doctor-patient relationship? Each assessment makes sense when all truth is relative or there is no good beyond the value of autonomy. In a simplified way, it could be said that, along with the fall of metaphysics, the object of the search is not objective truth about the person but rather right based on an individual idea of what is right. Thus, the good itself ceases to be important and the struggle for whom will reach their own goals prevails. Seemingly, the one common goal of both parties - that is, health — is divided into two interests.

\section{CONCLUSIONS}

It seems that the transition from the paternalistic model to one based on partnership has long been decided. Postmodernism - on the one hand supporting the individual's needs, on the other criticising the objective measure of order - has become a worldview favourable to protecting the patient's values. The modern patient increasingly often demands that his intuition regarding treatment be taken into account. It should be noted, however, that from the position of the patient these are not reflections solely focusing on the medical 
aspect of the disease. Health is a value belonging to the patient - and the patient does not treat his or her own body only as an instrument subjected to rational judgment (Wulff, Pedersen, \& Rosenberg, 1990). First of all, the patient is in a situation of illness, and therefore serious medical action involves a specific way of experiencing change and the need to find oneself in a new situation (Carel, 2012).

Allowing patients to ask questions and express their numerous doubts and their own axiology will never be a single discourse of a medical nature, an assessment of methods made from an intellectual perspective. The experience of illness always brings - in the words of Józef Tischner - a perspective of the "axiological Self", worried about one's own fate (Tischner, 2008: 33-46). The doctor's gestures are a subtle play on their sense of their own business. Losing health is a challenge to new axiological references. An athlete who considers vitality to be of high value suddenly loses the ability to easily attain it. The aesthetics of the body also change under the doctor's scalpel - posing a challenge for the patient to accept their new self. Patients may lose the value of aesthetic beauty, or vital strength, and may even have to fight to find the value of themselves such as they are in the face of a severe illness.

The doctor's lack of a sense of various types of values, or their deliberate skipping, may cause the patient to be treated instrumentally. Even when the doctor tries to bring the patient to the goal of being healthy in the light of medical knowledge, the patient can only serve as the means of the doctor's professional activity. It is no wonder, then, that, as a result of this, patients are beginning to look for ways to force doctors to recognise their right to self-determination.

Patients are articulating their needs or doubts increasingly boldly during visits. Specialists attached to the paternalistic approach do not provide space for the patient to actively participate in treatment-related decisions. They do not allow for partnership-based cooperation. The sick can interpret such behaviour on the part of the doctor only as an attack on their right to freely decide about themselves. However, things may be different - the doctor does not limit the patient's expansiveness to intentionally violate the patient's autonomy or in a fear of losing prestige or in order to reject and devalue the patient's subjective feelings. While ignoring the patient's values, the doctor may be guided by the objective to deepen the conversation on the therapy that is best from the perspective of the doctor's knowledge and experience. In fact, there is a danger that an increase in patients' needs will unrightfully entail a restriction on the fundamental goal of the medical profession. ${ }^{6}$

6 "A Doctor's calling is the protection of human life and health, prevention of disease, treatment of patients and relieving suffering. A doctor cannot use knowledge and medical skills in actions that are contrary to this calling”. From Article 2 Polish Code of Medical Ethics. 
Service is included in the ethos of this profession, and patients do not forget this. However, it should be noted that not every service is good. According to Plato's philosophy, such an assessment depends on the master whom one serves and the goals set by the master (Plato, 2004). While transferring this wisdom to the reality of the doctor's work, one would have to consider how to avoid the dangers associated with having the doctor-patient relationship driven by the patients' needs. It seems that doctors' legitimate claims exposed to ignorance, may dissolve in the dynamics of change or turn into a latent form of achieving their goals.

Leading is a significant feature of the doctor's role because the doctor is the one who helps and "pulls out" a weaker person from his or her difficult position (Schei, 2006). The repercussions of paternalism are still present; however, to emphasise the role of the patient, they find an escape in hidden and not necessarily moral ways that a professional may use to gain advantage. Focusing attention on the needs of the weakest sounds noble, so any open objection raised by the doctor could be interpreted as incompatible with the doctor's social role.

Currently - as was noted in the previous sections - quite a lot is being said about the values that are important to the patient. The doctor's axiology - in the sense of personal values - is considered far less. When values important to the doctor are discussed, those assigned to the ethos of this profession are usually taken into account.

It is also reasonable to conduct research and reflect on the experience of values in the doctor's work, including the philosophical concepts of values. Axiology is the field that provides knowledge about the existence of values, and describes how they are implemented and what they mean in interpersonal relations. This can be a support that is beneficial for deepening the knowledge about the conflict of values that doctors may experience when they find it difficult to act consistently with their own convictions.

A study entitled "The importance of the experience of values in the work of the doctor" is planned with regard to the issues presented here. It is expected to show doctors' efforts in the axiological aspect against the difficulties they currently encounter in their profession.

Doctors practise a profession of public trust and therefore must represent the standards that they follow. This is undoubtedly an essential aspect of the axiological description but not a sufficient one. There is no in-depth analysis of the contemporary doctors' personal efforts and difficulties they encounter while undertaking them. It would be valuable to illustrate the activities of physicians in this area because the identification of values does not always lead to actions that would be consistent with them. In other words - the values that doctors point to are not necessarily what they choose when handling their daily professional challenges. 
The proposed research emphasises the axiological perspective of the doctors. It focuses on the issue of the doctors shaping their attitudes - their experience of values, because it is the doctor who "hosts" the meeting and forms the axiological space where the patient can find him- or herself - or, conversely, feel excluded. The response to the patient's needs is connected with the question as to what the given person has to offer - whether they set any requirements for themselves, what change they pursue, are they ready to accept the patient?

From an ethical perspective, the starting point for such considerations is the assumption that the question of value must be addressed in the equilibrium to each party participating in an action. The principle of ethical conduct in which both persons - the doctor and the patient - are satisfied is that this conduct does not compromise the autonomy of either party (Kant, 1972). The values essential for the patient are taken into account in combination with the doctor's internal consent that these values are not contradictory to the doctor's values and direction of individual professional development.

\section{BIBLIOGRAPHY}

Anwar, S. \& Khan, S. (2013). Risks of online self-diagnosing: cyberchondriacs. British Columbia Medical Journal, 55(2), 72.

Bandol, R. (2015). Self-care as actualization of the human model in the philosophy of medicine. Postmodern Openings, 6(1), 35-53.

Barbaro, B. de. (2008). Why does psychotherapy need postmodernism?. Archives of Psychiatry and Psychotherapy, 10(3), 43-50.

Bardziński, F. (2017). O holistycznym modelu ludzkiej natury u Maine de Birana i Michela Henry. Filozofia i Nauka. Studia Filozoficzne i Interdyscyplinarne, 5, 89-104.

Beauchamp, T.A. \& Childress, J.F. (1994). Principles of biomedical ethics. New York: Oxford University Press.

Biesaga, T. (2013). Autonomia a godność osoby (pp. 169-183). In: G. Hołub, P. Duchliński, \& T. Biesaga (Eds.). Od autonomii osoby do autonomii pacjenta. Kraków: Wydawnictwo św. Stanisława BM.

Carel, H. (2012). Phenomenology as a resource for patients. Journal of Medicine and Philosophy, $37(2), 96-113$.

Charter of the United Nations, Preamble. Retrieved from: https://www.un.org/en/sections/un-charter/preamble/index.html (06.11.2020).

Chuengsatiansup, K. (2003). Spirituality and health: an initial proposal to incorporate spiritual health in health assessment. Environmental Impact Assessment Review, 23(1), 3-15.

Diaz, A. \& Honea, J. (2017). The effects of reductive physicalism within the field of mental healthcare. Dialogues in Philosopby Mental and Neuro Sciences, 10(2), 41-52.

Dworkin, G. (1988). The theory and practice of autonomy. New York: Cambridge University Press.

Emanuel, E.J. \& Emanuel L.L. (1992). Four models of the physician-patient relationship. The Journal of the American Medical Association, 267(16), 2221-2226.

Giddens, A. (1990). The consequences of modernity. Cambridge: Cambridge Polity Press. 
Grace, S.M. (2011). The clinician's voice of brain and heart: a biopsycho-ecological framework for merging the biomedical and holistic. Topics in Stroke Rebabilitation, 18(1), 55-59.

Health at a glance. (2015). OECD Publishing, Paris. Retrieved from: https://www.oecd-ilibrary.org/docserver/health_glance-2015-en.pdf (06.11.2020).

Heidegger, M. (1929). What is metaphysics. Retrieved from: http://www.stephenhicks.org/wp-content/uploads/2013/03/heideggerm-what-is-metaphysics.pdf (06.11.2020).

Heubel, F. (2000). Patients or customers: ethical limits of market economy in health care. Journal of Medicine and Philosophy, 25, 240-253.

Hołub, G. (2013). Co skrywa zasada autonomii? (pp. 141-168). In: G. Hołub, P. Duchliński, \& T. Biesaga (Eds.). Od autonomii osoby do autonomii pacjenta. Kraków: Wydawnictwo św. Stanisława BM.

Kant, I. (1972). Groundwork of metaphysics of morals. (H.J. Patont, Trans.). London: Hutchinson University Library.

Kępiński, A. (1977). Psychopatie. Warszawa: Państwowy Zakład Wydawnictw Lekarskich.

Meld. St. 11. (2015-2016). Nasjonal belse- og sykebusplan (2016-2019). Retrieved from: https:// www.mindbank.info/item/6405 (07.11.2020).

Mino, J.-C. \& Lert, F. (2005). Beyond the biomedical model: palliative care and its holistic model. Healthcare Ethics Committee Forum, 17(3), 227-236.

Mrówka, K. (2002). Ciało własne w filozofii Maine de Birana. Kwartalnik Filozoficzny, 30(4), $59-72$.

Mrzygłód, P. (2012). Jaka filozofia na dzisiejsze czasy...? Postmodernizm?. Perspectiva. Legnickie Studia Teologiczno-Historyczne, 2(21), 107-129.

Nilsen, S. \& Malterud, K. (2017). What happens when the doctor denies a patient's request? A qualitative interview study among general practitioners in Norway. Scandinavian Journal of Primary Health Care, 35(2), 201-207.

Pederson, S.N. \& Emmers-Sommer, T.M. (2012). "I'm not trying to be cured, so there's not much he can do for me": hospice patients' constructions of hospice's holistic care approach in a biomedical culture. Death Studies, 36, 419-446.

Pellegrino, E.D. (2008). The philosophy of medicine reborn. A Pellegrino reader. Indiana: University of Notre Dame Press.

Plato. (2004). The republic. (B. Jowett, Trans.). New York: Barnes \& Noble.

Ramsey, P. (2002). The patient as person: explorations in medical ethics. New Haven: Yale University Press.

Relman, A.S. (1980). The new medical-industrial complex. The New England Journal of Medicine, 303, 963-970.

Schei, E. (2006). Doctoring as leadership: the power to heal. Perspectives in Biology and Medicine, 49(3), 393-406.

Scheler, M. (1958). Man and bistory (pp. 65-93). In: M. Scheler, Philosopbical perspectives. (O.A. Haac, Trans.). Boston: Beacon Press.

Schwarz, E.R., Cleenewerck, L., Phan, A., Bharadwaj, P., \& Hobbs, R. (2011). Philosophical implications of the systemic and patient-oriented management of chronic heart failure. Journal of Religion and Health, 50, 348-358.

Stammers, T. (2015). The evolution of autonomy. The New Bioetbics, 21(2), 155-163.

Stineman, M.G. (2011). The clinician's voice of brain and heart: A biopsycho-ecological framework for merging the biomedical and holistic. Topics in Stroke Rebabilitation, 18(1), $55-59$.

Szary, S. \& Knotowicz, J. (2014). Różne oblicza holizmu w medycynie i fizjoterapii (pp. 7-17). In: A. Borowicz \& I. Kossowska (Eds.). Fizjoterapia wobec nowych wyzwań. Poznań: Wydawnictwo Wyższej Szkoły Edukacji i Terapii. 
Szewczyk, K. (2004). Debatujmy, poszukujmy, uprawiajmy (uwagi do wypowiedzi prof. Barbary Chyrowicz 'Bioetyka a metafizyka'). Diametros, 2, 184-195.

Szumowski, W. (2007). Filozofia medycyny. (A. Śródka \& R. Gryglewski, Eds.). Kęty: Wydawnictwo Marek Derewiecki.

Tischner, J. (2008). Axiological Pieces. (A. Fraś, Trans.) The Tischner Institute Journal of Philosophy, Agathology, 2, 33-46.

Veatch, R.M. (1979). Professional medical ethics: The grounding of its principles. The Journal of Medicine and Philosophy, 4, 1-19.

Welsch, W. (2008). Unsere postmoderne Moderne. Berlin: Akademie Verlag.

Wulff, H.R., Pedersen, S.A., \& Rosenberg, R. (1990). Philosophy of medicine: An introduction. Oxford: Blackwell Science. 